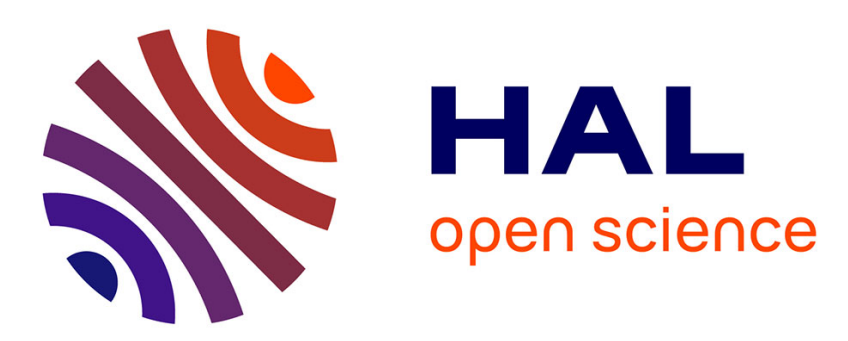

\title{
Inter-annual and inter-individual variations in survival exhibit strong seasonality in a hibernating rodent
}

Christie Le Cœur, Stéphane Chantepie, Benoît Pisanu, Jean-Louis Chapuis, Alexandre Robert

\section{- To cite this version:}

Christie Le Cour, Stéphane Chantepie, Benoît Pisanu, Jean-Louis Chapuis, Alexandre Robert. Interannual and inter-individual variations in survival exhibit strong seasonality in a hibernating rodent. Oecologia, 2016, 181 (3), pp.795-807. 10.1007/s00442-016-3597-2 . hal-01297596

\section{HAL Id: hal-01297596 https://hal.sorbonne-universite.fr/hal-01297596}

Submitted on 4 Apr 2016

HAL is a multi-disciplinary open access archive for the deposit and dissemination of scientific research documents, whether they are published or not. The documents may come from teaching and research institutions in France or abroad, or from public or private research centers.
L'archive ouverte pluridisciplinaire HAL, est destinée au dépôt et à la diffusion de documents scientifiques de niveau recherche, publiés ou non, émanant des établissements d'enseignement et de recherche français ou étrangers, des laboratoires publics ou privés. 
1 Inter-annual and inter-individual variations in survival exhibit strong seasonality in a

2 hibernating rodent

3 Christie Le Cour ${ }^{1}$, Stéphane Chantepie ${ }^{1,2}$, Benoit Pisanu ${ }^{1}$, Jean-Louis Chapuis ${ }^{1}$, Alexandre 4 Robert $^{1}$

$5{ }^{1}$ Centre d'Ecologie et des Sciences de la Conservation (CESCO UMR 7204), Sorbonne 6 Universités, MNHN, CNRS, UPMC, 43 rue Buffon, CP51, 75005, Paris, France.

$7 \quad{ }^{2}$ Université Grenoble Alpes, Laboratoire d'Écologie Alpine, CNRS, Grenoble, France

8 Corresponding author: Christie Le Cœur, Centre d'Ecologie et des Sciences de la 9 Conservation (CESCO UMR 7204), Sorbonne Universités, MNHN, CNRS, UPMC, 43 rue 10 Buffon, CP51, 75005, Paris, France. Tel +33 1407932 69, email-address: 11 christielecoeur@gmail.com

12 Keywords: mark-recapture, Tamias sibiricus, seasonal survival, hibernation, male-biased 13 mortality 


\section{Abstract:}

Most research on the demography of wild animal populations has focused on characterizing the variation in the mortality of organisms as a function of intrinsic and environmental characteristics. However, such variation in mortality is difficult to relate to functional life history components (e.g. reproduction, dispersal, hibernation) due to the difficulty in monitoring biological processes at a sufficiently fine timescale.

In this study, we used a 10-year individual-based data set with an infra-annual timescale to investigate both intra- and inter-annual survival patterns according to intrinsic and environmental covariates in an introduced population of a small hibernating rodent, the Siberian chipmunk. We compared three distinct periods related to particular life history events: spring reproduction, summer reproduction and hibernation. Our results revealed strong interactions between intrinsic and temporal effects.

First, survival of male chipmunks strongly decreases during the reproduction periods, while survival is high and equal between sexes during hibernation. Second, the season of birth affects the survival of juveniles during their first hibernation, which does not have longlasting consequences at the adult stage. Third, at an inter-annual scale, we found that high food resource availability before hibernation and low chipmunk densities specifically favour subsequent winter survival. Overall, our results confirm that the well-known patterns of yearly and inter-individual variation of mortality observed in animals are themselves strongly variable within a given year, suggesting that they are associated with various functional components of the animals' life history. 


\section{Introduction}

The mortality risk faced by wild animals depends on their intrinsic conditions [e.g. age-related experience, body condition, quality of immune system (e.g. Forslund and Part 1995; Chantepie et al. 2015; Théoret-Gosselin et al. 2015)], their instantaneous energetic requirements, which vary according to the life history component that they are experiencing, such as reproduction or migration (e.g. Clutton-Brock 1988; Kirkwood and Rose 1991), and their exposure to extrinsic sources of mortality [e.g. adverse climatic conditions, disease, predation (e.g. Coulson et al. 2001)]. Thus, understanding the processes underlying mortality requires characterization of the variations in the mortality of organisms as a function of their characteristics (e.g. young vs. old, male vs. female), their conditions (e.g. spatial, or temporal variation, e.g. habitat, resource availability) and their actions (e.g. foraging, breeding, dispersing, migrating, hibernating, etc.), which requires in turn the monitoring of biological processes at a sufficiently fine timescale (e.g. Grant et al. 2005; Kraus et al. 2008; Hardouin et al. 2012, 2014). Recent demographic studies have shown that precise information on individual statuses can be used to gain insight into the relationships between mortality and some functional life history components. For example, the relationship between reproduction and mortality can be approached through comparisons between the survival of breeders and non-breeders using multi-state modelling (Robert et al. 2012). However, such approaches (1) require data on individual statuses, which are often lacking; (2) do not allow for the study of fine timing (e.g. seasonal pattern) of mortality if sampling is conducted at a larger timescale (e.g. an annual time step); and (3) cannot be used if no variance exists within the population with respect to the life history component of interest (e.g. if all individuals in the population breed, migrate or hibernate).

In virtually all natural environments, the biology and ecology of organisms are affected by climatic seasonality leading to seasonal variations in life history components and cyclicity in 
iteroparous organisms that can live several years. In such species, a long-term survival assessment conducted at an appropriate infra-annual timescale is a method of gaining insight into the processes associated with mortality, notably by understanding (1) how intra-annual patterns of mortality vary between seasons prominently associated with particular components of the life history (e.g. breeding, migration, hibernation); (2) how specific seasonal variation in biotic (e.g. abundance of resources, interspecific interactions) and abiotic factors (e.g. changes in local meteorological conditions) affects patterns of mortality across seasons (e.g. Aars and Ims 2002; Rödel et al. 2004); and (3) how these intra-annual variations contribute to overall mortality and its inter-annual variation (e.g. Kraus et al. 2008; Kerbiriou et al. 2009; Duriez et al. 2012; Leyrer et al. 2013; Noël et al. 2013; Radchuk et al. 2014).

In mammals, the energetic investment of reproduction is particularly important in females during gestation and lactation (Gittleman and Thompson 1988), as well as in males in their mating behaviour [including male-male competition, energy and time expenditure to locate and mate with females (e.g. Lane et al. 2010)]. In relation to finite internal energy reserves (Stearns 1989, 1992; Roff 1992), energy allocation to reproduction is predicted to be costly and may involve fitness costs, such as a decrease in short- and long-term fecundity or survival (e.g. Descamps et al. 2009; Hamel et al. 2010). Such investments and associated costs induce a seasonality of breeding at the most energetically favourable periods, particularly in temperate latitudes (Bronson 2009). The high-energy cost of reproduction events contrasts with hibernation, which in temperate-zone mammals is generally regarded as an energysaving strategy to survive seasonal periods of energy shortage (harsh climatic condition, food or water shortage), ensuing from pre-hibernal energy storage [body fat reserves and/or food storage (Humphries et al. 2003)] and/or hibernal metabolic depression (Heldmaier 1989; Wang 1989). Although physiological costs are involved in torpor and arousal patterns [e.g. decreased immunocompetence (Prendergast et al. 2002)], the hibernation period seems to be 
associated with high monthly survival probabilities over winter, compared with the active season, and appears to have a positive effect on the lifespan of mammal hibernators (Wilkinson and South 2002; Humphries et al. 2003; Turbill et al. 2011).

In the present study, we examine both intra- and inter- annual survival patterns in a small iteroparous mammal, with an emphasis on three contrasting seasons related to particular life history events: reproduction (two seasons), and hibernation. Although reproduction and hibernation are hypothesized to affect the seasonal pattern of survival, surprisingly few studies have attempted to assess the survival rates of free-living mammals during both the active and hibernation seasons (e.g. Bieber et al. 2012; Bergeron et al. 2013). To tackle this question, we analysed capture-mark-recapture data collected over 10 years, with an infraannual resolution, on the Siberian chipmunk (Tamias sibiricus), a small mammalian hibernator introduced to an oak-hornbeam forest in France. In its introduced area, this species is characterized by two reproductive seasons (in early spring and early summer) and a hibernation period (from September-October to March); the beginning, the emergence and the duration of these depend on individual age and sex, as well as environmental conditions in which individuals hibernate in underground burrows with stored food [mainly tree seeds (Chapuis et al. 2009)].

We first quantify the inter- and intra-annual variation in survival of the Siberian chipmunks in relation to age and sex. Because the timing of births can affect survival (e.g. Feder et al. 2008), we examined whether spring-born and summer-born juveniles differ in their probability to survive the first hibernation period, as well as in their survival rates as adults (after the first winter). Second, we focus on the potential influence of environmental conditions on seasonal patterns of survival, including the effects of local meteorological conditions, food availability prior to hibernation, population density and winter groundwater height, used as an index of potential death-related burrow flooding. 
We predict that the mortality probability per unit of time will be lower during the hibernation

period than during the reproductive periods, and we test whether this seasonal pattern will be influenced by age, sex and/or birth season. Because chipmunks do not rely on the same resources in the different seasons, the inter-annual differences in survival are expected to vary between seasons (i.e. we predict an interaction between seasons and years on survival). Additionally, we hypothesize that food availability and chipmunk density before the hibernation period, as well as the meteorological conditions and high groundwater height in winter, are likely to influence survival during and immediately after hibernation (for resource availability only).

\section{Material and methods}

\section{Study species}

Siberian chipmunks Tamias sibiricus are short-lived, ground-dwelling, solitary and sedentary sciurids native to Asia that were introduced into Europe to be sold as pets from the 1960s (Chapuis et al. 2009). Siberian chipmunk populations were observed a decade after their introduction in several European suburban forests and urban parks, including 11 settled populations recorded in France (Chapuis et al. 2009; Pisanu et al. 2013).

In France, chipmunks hibernate from September-October to February-March [the beginning and duration of hibernation and an individual's emergence depend on individual age and sex, as well as environmental conditions (Chapuis et al. 2009)] and can reproduce twice a year. They use a single burrow to hibernate and several burrows during the year. This promiscuous species exhibits a scramble competition mating system with a mating season extending from the hibernation emergence date until the first half of July with two peaks in births: one in the spring (i.e. mainly in April with juveniles emerging from their birth burrow from May to early June) and the second in the summer [i.e. mainly in July with emergence from late August to September (Marmet et al. 2012)]. All juveniles were classified as either 'spring-born' or 
'summer-born'. Regardless of the birth season, individuals become sexually mature in their second year (after their first hibernation) without sexual size dimorphism. Consequently, individuals were considered as adults the year following their birth. Before entering hibernation, adults and juveniles stored food (tree fruits-Quercus spp., Carpinus betulus, Prunus avium) within their burrows, providing energy reserves during the hibernation period, characterized by repeated arousals from torpor (Chapuis et al. 2009). In the summer, the chipmunk diet is wide ranging and mainly composed of insects (e.g. Coleoptera, Lepidoptera), fruits (e.g. cherry, hazelnut, blackberry) and herb seeds (Chapuis et al. 2009).

\section{Study site and monitoring}

Population monitoring has been conducted since 2004 at the La Faisanderie site (14 ha; $48^{\circ} 39^{\prime} \mathrm{N}, 02^{\circ} 29^{\prime} \mathrm{E}$ ), located in the temperate Sénart Forest (3200 ha), $22 \mathrm{~km}$ south-east from Paris. The study area consisted of three main types of habitats: a 6-ha semi-open oak grove (herbaceous layer, $90 \%$; shrubby layer, $5 \%$; arboreal layer, $60 \%$ dominated by Quercus robur and Quercus petraea), a 6.5-ha closed oak-hornbeam grove (herbaceous layer, $10 \%$; shrubby layer, $30 \%$; arborescent layer, $90 \%$ dominated by $Q$. robur, Q. petraea, and $C$. betulus), and a mix of grassland and buildings representing an additional 1.5 ha (Marmet et al. 2009).

The population has been monitored using capture-mark-recapture methods. Throughout the study site, chipmunks were live trapped in baited Sherman traps during their main activity period from March to October. A grid consisting of 80 geo-localised traps was used in 2004 and was surrounded by 24 extra traps during the subsequent years [see description in Marmet et al. (2009)]. Two monthly capture sessions were performed at 15-day intervals, each consisting of 3 and 2 consecutive trapping days in 2004 and 3 and 5 consecutive days between 2005 and 2007. From 2008 onward, only a 5-day-long trapping session was conducted each month. At first capture, individuals were ear tagged and implanted with a subcutaneous 
transponder chip (Marmet et al. 2009). At each trapping event, the date and trap location were recorded, as well as the chipmunk identity. Body mass, age (adult or juvenile, based on the date of capture and body mass), birth season (spring-born or summer-born chipmunks) and sex were also noted at the first capture of an individual in a trapping session. Some individuals could not be aged and were assigned as undetermined for age and birth season. After being handled, the chipmunks were released at their point of capture.

\section{Environmental factors}

Due to the lack of data at our study site prior to 2006, we used an ordinal mean acorn production index in nearby forests covering the 2004-2013 period (National Forests Office, unpublished data; Online Resource 1), which was related to both the oak fructification index and the averaged spring acorn biomass in our study site (acorn index categories -0 , none or few acorns/small crop size; 1, medium; and 2, large crop size; Online Resource 1). Due to the wide range of potential dietary items in summer, resource availability could not be quantified. Therefore, spring temperatures were used as a cue to identify the availability of resources in the summer because temperature is a main driver of many developmental processes, including plant development (Badeck et al. 2004). Additionally, we used monthly mean temperatures and precipitation (Méteo-France data, Melun-Villaroche station), together with groundwater height measured by piezometry (Bureau de Recherches Géologiques et Minières data, Montereau-sur-le-Jard station), as proxies for local meteorological data as no data were available for our study site in Sénart Forest, located approximately ca. $15 \mathrm{~km}$ away in a northwesterly direction (Online Resource 1). From capture-recapture, the monthly densities of chipmunks (adults and juveniles for each sex separately) in April, June, and July were estimated from spatially explicit capture-recapture models [SECR (Efford et al. 2009)]. Age and sex were accounted for in SECR models because of known distinct space use behaviours (Marmet et al. 2009, 2011, 2012), which may have affected both capture probabilities and 
movement scales. We also tested for individual learned response to specific traps (Marsot et al. 2013), which has been found to be a consistent behaviour for chipmunks in our population (Boyer et al. 2010; Le Coeur et al. 2015b). Estimated densities for each sex were then summed for each age (Online Resource 1).

\section{Survival analysis using Huggin's robust design}

We analysed capture history data collected from 2004 to 2013 with Huggins's closed capture models within the robust design framework (Huggins 1989; Kendall et al. 1997; Hines et al. 2003). All models were performed in the program MARK (White and Burnham 1999), which was accessed through the R (R Core Team 2014) package RMark version 2.1.6-1 (Laake and Rexstad 2014). This design provided a precise estimation of survival rates by controlling for unbiased capture and recapture probabilities and taking temporary migration into account (Kendall et al. 1997). Five parameters were estimated, including survival $(S)$, first capture $(p)$, recapture $(c)$, temporary emigration $\left(\gamma^{\prime \prime}\right)$ and temporary immigration $\left(1-\gamma^{\prime}\right)$ probabilities. Unlike Pollock's (1982) robust design, abundance parameter $(N)$ is computed as a derived parameter (i.e. outside the likelihood) from estimated capture probabilities and observed data (i.e. number of captures). One advantage of these models is that chipmunk hibernation can be modelled as temporary emigration (see Kendall et al. 1997; Kendall and Bjorkland 2001).

In relation to important life history components (hibernation, first and second reproduction), April, June and August were selected as three primary sessions per year. Each of these three primary sessions consisted of 3 (in 2004) or 5 (from 2005) trapping days at the beginning of each month, hereafter referred to as 'secondary trapping sessions'. Then, the full sampling design was composed of 30 primary sessions involving 144 secondary trapping sessions, resulting in 1962 capture records (recaptures of an individual occurring the same day were not included) of 526 individually marked chipmunks (individuals with known age, sex and birth season only; see details in Online Resource 1) during the 10-year monitoring study (2004- 
2013). Six groups were defined according to the sex, age (juvenile or adult; individuals of undetermined age were not considered) and birth season (spring-born or summer-born individuals; individuals with unknown birth season, i.e. marked as adult or undetermined age, were not considered) of chipmunks. Four hundred and ten chipmunks were marked as springborn juveniles and 116 as summer-born juveniles. In addition, inter- and/or intra-annual variations (i.e. year, season and full-time variabilities) were tested as additive or interaction terms for the five estimated parameters. Based on this model design, we defined three seasons, spring (April-June), summer (June-August) and fall-winter (August-April). Because a full interaction general model would be over-parameterised, the most general model that was considered included interactive effects of year, season, sex, age and birth season for $S, \gamma^{\prime \prime}$ and $\left(1-\gamma^{\prime}\right)$, interactive effects of session, sex and birth season for $c$, and interactive effects of sex and birth season for $p$ (see description and notations in Table 1). To allow for the comparison of estimates between seasons, we specified uneven time intervals between sampling occasions (expressed in numbers of months), such that $S, \gamma^{\prime}$ and $\gamma^{\prime \prime}$ are expressed as monthly probabilities (unless specified otherwise). Parameters values are given as the mean \pm SE.

Model selection was based on Akaike's information criterion adjusted for small sample size (AICc) (Burnham and Anderson 2002). As a general approach, we started model selection by testing temporal and group effects and their interaction on capture and recapture probabilities, then used the most-parsimonious models of $p$ and $c$ to model the emigration parameters $\left(\gamma^{\prime}\right.$ and $\gamma^{\prime \prime}$ ) and finally $S$ (the complete set of models tested is available in Online Resource 2). Random and Markovian temporary emigration were both tested in this analysis [i.e. for random and Markovian movement, respectively, the probability of moving between availability states between primary occasions $i$ and $i+1$ is independent/conditional on the state of the individual at time $i-1$ (Kendall et al. 1997)]. 


\section{Goodness-of-fit testing}

Prior to model selection, the capture-mark-recapture data set was tested for any violations of the assumptions under the robust design (see details in Online Resource 3). Both the closure assumption within primary sessions (i.e. the population is assumed closed to additions and deletions within a primary session) and the detection of individual heterogeneity in capture probabilities were tested with the software CloseTest (Stanley and Burnham 1999) and CAPTURE (Rexstad and Burnham 1992), respectively. Because goodness-of-fit (GoF) tests have not been developed for the robust design, we used two different approaches to test the fit of our data. First, the GoF of the general model was tested using the approach based on cellpooling contingency tests implemented in the software RDSURVIV (Kendall and Hines 1999). No overdispersion was revealed $(c$-hat $=1)$. Second, we tested the fit of data to an open population model using U-CARE (Choquet et al. 2009), which indicated 'underdispersion' ( $c$-hat $=0.45)$. We thus applied a conservative approach for variance adjustment (i.e., $c$-hat $=1$; Online Resource 3) (Cooch and White 2014).

\section{Temporal covariates}

Starting from the most parsimonious model, we tested whether the variation in environmental covariates including (1) local meteorological variables (based on mean seasonal temperatures and precipitation during the three time intervals related to the sampling design), (2) environmental conditions (groundwater height, resource availability from oak fructification index), and (3) chipmunk densities (juveniles and adults), was related to the variation in survival probabilities based on an analysis of deviance (ANODEV) (Skalski et al. 1993; see models tested in Online Resource 4, with a significance threshold fixed at $\alpha=0.05$ ). An alternative model considering a composite covariate derived from a principal component analysis on the three temporal covariates (oak fructification index, mean air temperature in 
259 fall-winter and population density in July) was performed and yielded similar results (Online Resource 5).

261

262

\section{Life expectancy}

Mean annual survival rates estimated for each age-class (juveniles and adults; $a$ ) were used to estimate adult life expectancy depending on the sex and birth season $(b)$ of chipmunks (LE=$\left.1 / \ln \left(\phi_{(a * b+s e x)}^{\text {annual }}\right)\right)$. Alternatively, more precise estimates of life expectancy at emergence from the birth burrow were computed based on stochastic simulations, using monthly survival estimates and taking into account the difference in the duration of the 'juvenile stage' between spring-born and summer-born individuals (i.e. the time elapsed from emergence from their birth burrow to the end of their first hibernation; all details presented in Online Resource 6).

\section{Results}

\section{Annual and seasonal patterns of survival}

The most parsimonious model $\left[S_{\left.(\text {seas*(year }+\operatorname{sex})+\mathrm{b}^{* a}\right)} \gamma^{\prime}\right.$ and $\left.\gamma^{\prime \prime}{ }_{(\text {seas markovian) }} c_{(\text {sess })} p_{(.)}\right]$revealed constant capture probabilities over time $(p=0.32 \pm 0.02)$, temporal effects of season in interaction with year on $c$, seasonal Markovian temporary migration rates $\left(\gamma^{\prime \prime}\right.$ and $\left.\gamma^{\prime}\right)$, and the influence of birth season, age and their interaction with an additive effect of sex and year in interaction with the seasons [i.e. seas $\times($ year $+\operatorname{sex})+b \times a$ ] on $S$ (model 59; Table 2).

Survival probabilities fluctuated over seasons and years (seas $\times$ year interaction; Fig. 1), and annual survival rates ranged from $0.17 \pm 0.06$ in 2012 to $0.69 \pm 0.09$ in 2005 (model 79) with a mean of $0.28 \pm 0.02$ (model 93). We found no strong differences in inter-annual variation among seasons, suggesting that the inter-annual pattern of survival was not shaped by a specific, highly variable season between years.

The seasonal pattern of survival (expressed as monthly survival probability; Fig. 2a) was characterized by high monthly winter survival (on average $S_{\text {fall-winter }}=0.91 \pm 0.01$; model 94) 
and slightly lowered survival throughout the active period $\left(S_{\text {spring }}=0.88 \pm 0.03, S_{\text {summer }}=0.87\right.$ \pm 0.04 ; model 94). The survival difference between the hibernation and breeding periods was low, but considering distinct survival rates between spring and summer (on the one hand) and winter (on the other) slightly improved model quality (compare, e.g. models 74 and 76 in Table 2). Consequently, the probability of surviving the 8-month fall-winter season and the 4month active period was $0.47 \pm 0.05$ and $0.59 \pm 0.06$, respectively.

This seasonality was strongly influenced by sex, age and birth season (Fig. 2b). At both the juvenile (juv.) and adult (ad.) stages, males suffered high mortality in the summer $\left(S_{\text {spring-born }}\right.$ juv. $=0.70 \pm 0.05 ; S_{\text {spring-born ad. }}=0.75 \pm 0.05$ and $S_{\text {summer-born ad. }}=0.78 \pm 0.04 ;$ model 80 ), whereas summer female mortality was low $\left(S_{\text {spring-born juv. }}=0.93 \pm 0.05 ; S_{\text {spring-born ad. }}=0.94 \pm\right.$ 0.04 and $S_{\text {summer-born ad. }}=0.95 \pm 0.03$; model 80). Additionally, we found that juvenile chipmunks had substantially lower survival probabilities than adults, regardless of their sex (annual survival rate, $S_{\text {juv. }}=0.23 \pm 0.03$ and $S_{\text {ad. }}=0.32 \pm 0.03$; model 90). In juveniles, a significant difference in the survival rates between spring-born and summer-born juveniles occurred when both cohorts overlapped (fall-winter interval). We report a higher survival of spring-born juveniles $(0.90 \pm 0.01$ and $0.92 \pm 0.02$ for females and males, respectively) than summer-born juveniles $(0.81 \pm 0.06$ and $0.84 \pm 0.05$ for females and males, respectively; model 80).

The sex-biased effect in adult survival was associated with notable sex differences in adult life expectancy. The adult life expectancy was approximately 1 year for females and 9 months for males. More precise estimates of life expectancy, computed at emergence from the birth burrow and accounting for the birth season of individuals, revealed that the life expectancy at emergence from the birth burrow ranges from 4.5 months for summer-born males to 10.5 months for spring-born females (details presented in Online Resource 6). 
Recapture probabilities varied among primary sessions and ranged from $0.11 \pm 0.03$ in June 2010 to $0.80 \pm 0.18$ in April 2004 (model 5; see Online Resource 2, Table 2.2) with a mean of $0.38 \pm 0.01$ (model 16). During the 10 -year study, the mean seasonal recapture probability was lower in August $\left(c_{\text {August }}=0.28 \pm 0.02\right)$ than in April and June $\left(c_{\text {April }}=0.41 \pm 0.02\right.$ and $c_{\text {June }}=0.41 \pm 0.01 ;$ model 12 Online Resource 2).

The average seasonal estimate of Markovian temporary emigration rate for animals present during the previous period $\left(\gamma^{\prime \prime}\right)$ was the lowest in spring and peaked during summer $\left(\gamma^{\prime \prime}\right.$ spring $=$ $0.12 \pm 0.06, \gamma_{\text {summer }}^{\prime \prime}=0.51 \pm 0.04$ and $\gamma^{\prime \prime}{ }_{\text {fall-winter }}=0.36 \pm 0.07$; model 59) whereas the temporary emigration rates for animals absent in the previous primary session $\left(\gamma^{\prime}\right)$ were higher and similar between seasons $\left(\gamma_{\text {spring }}^{\prime}=0.49 \pm 0.10, \gamma_{\text {summer }}^{\prime}=0.63 \pm 0.12\right.$ and $\gamma_{\text {fall-winter }}^{\prime}=0.55 \pm$ 0.07; Model 59).

\section{Temporal covariates}

Temporal covariates, including the fructification index and the mean fall-winter temperatures, were significantly correlated (linearly) with the fall-winter survival probabilities of chipmunks $\left[R^{2}=54 \%, P\right.$-value $=0.02$, model $103 ; R^{2}=47 \%, P$-value $=0.04$, model 108 ; Fig. 3; Online Resource 4]. A threshold was reached at the fructification index 1 (i.e. medium quantity of acorns), from which survival was significantly higher than for index 0 (i.e. none or few acorns). Additionally, we found that adult densities in April, June and July were slightly negatively correlated with spring, summer and fall-winter survival, respectively $\left(R^{2}=13 \%\right.$, $P$-value $=0.05$, model 118; Fig. 4). These results suggest that higher resource availability before hibernation, a warm winter and low chipmunk density favoured the probability to survive the fall-winter. Spring temperatures, which are used to identify the availability of resources in summer, are marginally related to summer survival $\left(R^{2}=41 \%, P\right.$-value $=0.06$, model 112). No other correlation was found (see ANODEV results and figures in Online Resource 4). 
In iteroparous organisms that can live several years, the mortality risk is generally strongly influenced by the sex and age of individuals, as well as by year-to-year environmental variations including fluctuations in resources, meteorological conditions, competition, predation and their interacting effects (e.g. Loison et al. 1999; Coulson et al. 2001). However, such variation in mortality is difficult to relate to functional life history components due to the difficulty in monitoring biological processes at a sufficiently fine timescale. Relying on individual-based data collected at an infra-annual timescale in Siberian chipmunks, our study uncovered strong relationships between overwinter survival and several environmental factors, including resource availability, meteorological conditions and chipmunk density. More generally, we provided original insights about survival variation during the reproduction and hibernation periods and highlighted that strong sex-specific mortality occurs only at a specific period of the year.

In the population of Siberian chipmunks, the seasonal pattern of survival is characterized by high monthly winter survival (hibernation season, on average $S_{\text {fall-winter }}=0.91 \pm 0.01$ ) and slightly lower but comparable survival throughout the active period (breeding seasons, $\mathrm{S}_{\text {spring }}$ $=0.88 \pm 0.03$ and $S_{\text {summer }}=0.87 \pm 0.04$, Model 94; Fig. 2a). Equally high winter survival of adult chipmunks is observed, regardless of their sex and birth season. Although high monthly winter survival has been observed previously in other hibernating mammals (Turbill et al. 2011), the seasonal pattern of chipmunk survival differs from those reported by previous studies on small European hibernating mammals of similar size and with a comparable duration of hibernation, such as the common dormouse, Muscardinus avellanarius (Bieber et al. 2012) and the edible dormouse, Glis glis (Lebl et al. 2011). In such species, the survival pattern was characterized by an increase in survival probabilities throughout the year, with the lowest survival in the early active season, an increase in late summer and the highest survival 
in winter. Moreover, in these species, as well as in the garden dormouse, Eliomys quercinus (Schaub and Vaterlaus-Schlegel 2001), the probability of surviving the hibernation period (monthly timescale) at the adult stage is close to unity, whereas in our population, the winter survival probability, related to the fall and hibernation periods, is much lower, an average of 0.92 for adults. These differences can be attributed to distinct life histories in glirids compared with Siberian chipmunks, related to the activity time (nocturnal in glirids), as well as the energy storage strategy during hibernation (fat in glirids versus food hoarding in chipmunks). Among closely related species, such as eastern, shadow and long-eared chipmunks, high overwinter survival rates comparable to those of our population have been reported [respectively, Tamias striatus (Bergeron et al. 2013), Tamias senex and Tamias quadrimaculatus (Wilson et al. 2008)]. The seasonal pattern of survival (summer and winter estimates) in the eastern chipmunk was also found to be similar to the pattern found in our study (Bergeron et al. 2013).

Most importantly, we found that the seasonality of survival strongly differed between sexes. Although male-biased mortality at a yearly time resolution was detected (in adults: $\mathrm{S}_{\text {males }}=$ $0.25 \pm 0.03, S_{\text {females }}=0.35 \pm 0.03$; Model 84 ), our results show that this sex difference only occurs in summer. In adult females, we underline a similar survival pattern among seasons, as found in the other small mammal hibernators previously cited (although with slightly lower survival in the winter than in the late active period; in adult chipmunks: $S_{\text {spring }}=0.86 \pm 0.03$, $S_{\text {summer }}=0.95 \pm 0.04$ and $S_{\text {fall-winter }}=0.92 \pm 0.01$; Model 81). In contrast, males clearly suffer from higher mortality in summer than in other seasons (in adults, $S_{\text {spring }}=0.86 \pm 0.04, S_{\text {summer }}$ $=0.77 \pm 0.04$ and $S_{\text {fall-winter }}=0.93 \pm 0.01$; Model 81). This survival pattern was associated with substantial differences in the adult life expectancies of males and females.

Higher mortality rates and shorter lifespans in males than in females are commonly observed among mammal species (Neuhaus and Pelletier 2001; Clutton-Brock and Isvaran 2007; Kraus 
et al. 2008). Various but interrelated hypotheses have been proposed to explain juvenile and adult male-biased mortality: 1) Lower immunocompetence of males, which increases their susceptibility to infectious disease and parasitism (Moore and Wilson 2002); 2) The costs of sexual size dimorphism in the larger sex, usually males in polygynous or promiscuous mammals (Promislow 1992; Moore and Wilson 2002); 3) The higher propensity of males to engage in potentially risky behaviours, such as dispersal, sexual competition and roaming (Greenwood 1980; Andersson 1994; Kraus et al. 2008); 4) The potential effects of deleterious recessive alleles in the heterogametic sex (XY) (e.g. Libert et al. 2010) and 5) In polygynous species with sexual size dimorphism, a high mortality of male juveniles in relation to a biased mother's investment or adjustment of the sex of their offspring (Clutton-Brock et al. 1985; West and Sheldon 2002), which can also influence later adult mortality patterns (Lindström 1999; Garratt et al. 2015).

In Siberian chipmunks, the difference in the observed pattern between male and female survival may be primarily due to their specific mating system and associated behaviour. They are monomorphic and exhibit a scramble-competition mating system with promiscuity (Obolenskaya et al. 2009; Marmet et al. 2012), occurring from late February-March until the first half of July. As a consequence, the hypotheses related to sexual size dimorphism effects on juvenile and adult survival can be rejected. According to the scramble-competition mating system, male-male competition is associated with high mate-searching efforts rather than physical or aggressive behaviour (Lane et al. 2010). In our study population, male chipmunks were found to increase their space use to increase their chances of meeting and fertilizing females (Marmet et al. 2012). This activity (associated with both breeding and roaming behaviours) can induce high energetic costs for males which may exceed the corresponding cost of female gestation and lactation (e.g. Lane et al. 2010) and can increase their risk of predation and parasitism exposure during the breeding season (e.g. Krasnov et al. 2005; Boyer 
et al. 2010; Le Coeur et al. 2015a). The absence of sex difference in overwinter survival suggests a prominent role of risk-based processes over energy-based explanations. The two remaining and non-mutually exclusive hypotheses of costly sexual risky behaviour and immunocompetence handicap may then explain the low survival of males, as reported at the end of the mating season.

Among juveniles (i.e. non-reproductive individuals), lower male survival in summer was also reported. Because no sexual size dimorphism was found and the sex ratio is balanced among juveniles for both cohorts (from the capture-recapture data; Online Resource 1), we exclude the hypothesis of a biased parental investment. Marmet et al. (2011) previously showed in the study population that natal dispersal distances are farther in males than in females. Consequently, sex differences in estimates of apparent survival of juveniles may arise due to both a higher survival cost of dispersal in males and higher rates of permanent emigration from the study site.

When the two birth season cohorts overlap in the fall-winter interval (August-April), sex differences are no longer detected among juveniles, but a strong birth season cohort effect was 422 observed, in which summer-born juveniles showed lower survival probabilities than springborn juveniles. In environments with marked seasonal differences, the timing of births can have important fitness consequences (e.g. Kraus et al. 2005; Feder et al. 2008; Bieber et al. 2012). The observed phenomenon can be attributed to the short time available to summerborn juveniles for growth, to find a new suitable burrow and to store enough food before 427 hibernation to survive the winter. At the adult stage, the birth season cohort differences disappear (Fig. 2b).

429 Finally, we found that the seasonality of survival varied substantially among years (Fig. 1). 430 We observed in particular that (1) inter-annual variations in survival are not strongly 
correlated among seasons (i.e. Year and Season effects are non-additive), and (2) overall annual survival variations are not shaped by a particular, highly variable season (i.e. there is similar inter-annual variance among seasons).

Our results suggest that high resource availability before hibernation, as well as good winter meteorological conditions and lower chipmunk densities (slight effect), may favour the winter survival of chipmunks (Figs. 3, 4; see also the analysis based on composite covariate in Online Resource 5). In the chipmunk, a food-storing hibernator, the availability of energy-rich seeds, including oak and hornbeam fruits and wild cherry seeds, before hibernation could be a key factor influencing their foraging behaviour in late summer/fall, their hibernation survival and potentially their reproduction in the next spring (e.g. Humphries et al. 2003). Associated with resource availability, a high density of conspecifics can increase intraspecific competition processes on foraging and storing food, as well as competition for hibernation nests (Kawamichi 1996). Nevertheless, this relationship may be shaped by marginal years such as 2008, which was characterized by an acorn crop failure in the fall, and the highest chipmunk density and the coldest winter of the time series (i.e. nine winter periods; Figs. 3, 4) were observed. Moreover, the correlation between the fructification index and the winter temperature can be confusing when determining which variable is the influential one (see Online Resource 4, Fig. 4.2). In their native area, Siberian chipmunks live in a wide range of environmental conditions, including harsher winter conditions than the local temperate conditions encountered in the study population (Chapuis et al. 2009), which makes the winter temperature effect the least likely hypothesis. Further investigations of longer time series are necessary to confirm these results and disentangle the effects of the various covariates.

\section{Conclusion}

Studying the seasonality of survival pattern in the Siberian chipmunk, a small hibernating mammal, allowed us to highlight strong intra-annual variation of survival among ages and 
sexes in relation with two main life history events, the reproduction and the hibernation. Our results illustrate that accounting for intra-annual time scale in survival pattern can help improve our understanding of the relationship between a key fitness component, i.e., survival, seasonal life history events and environmental variations. The hypotheses developed to explain costly reproductive behaviour on male survival should be further investigated by performing complementary analyses on simultaneous reproduction and mortality patterns in the Siberian chipmunk population. From high winter survival, our results seem to support the fact that hibernation can favour slower life histories of hibernators by increasing their survival, compared with non-hibernating small rodents of similar size (Turbill et al. 2011).

Acknowledgements We are thankful to the National Forests Office (Office National des Forêts, France) for financial support and for allowing fieldwork in the site 'La Faisanderie' (Forest of Sénart, France). This work was also funded by the Conseil Régional d'Ile-deFrance, the Conseil Départemental des Hauts-de-Seine and the Ministère de l'Ecologie, du Développement durable et de l'Energie (MEDDE). We are thankful to J. Marmet and M. Marsot for their contribution in mark-recapture monitoring. We wish to thank J.E. Hines for his helpful explanations on RDSURVIV and CAPTURE softwares and A. Bel (BRGM Ile-deFrance) for sharing data from Champigny groundwater.

\section{References}

Aars J, Ims RA (2002) Intrinsic and climatic determinants of population demography: the winter dynamics of tundra voles. Ecology 83:3449-3456.

Andersson MB (1994) Sexual selection. Princeton University Press

Badeck F-W, Bondeau A, Bottcher K, et al. (2004) Responses of spring phenology to climate change. New Phytol 162:295-309. doi: 10.1111/j.1469-8137.2004.01059.x

Bergeron P, Montiglio P-O, Réale D, et al. (2013) Disruptive viability selection on adult 
exploratory behaviour in eastern chipmunks. J Evol Biol 26:766-774. doi:

\subsection{1/jeb.12081}

Bieber C, Juškaitis R, Turbill C, Ruf T (2012) High survival during hibernation affects onset and timing of reproduction. Oecologia 169:155-66. doi: 10.1007/s00442-011-2194-7

Boyer N, Réale D, Marmet J, et al. (2010) Personality, space use and tick load in an introduced population of Siberian chipmunks Tamias sibiricus. J Anim Ecol 79:538-547. doi: 10.1111/j.1365-2656.2010.01659.x

Bronson FH (2009) Climate change and seasonal reproduction in mammals. Philos Trans R Soc Lond B Biol Sci 364:3331-3340. doi: 10.1098/rstb.2009.0140

Burnham K, Anderson D (2002) Model selection and multi-model inference: a practical information-theoretic approach. Springer Science \& Business Media

Chantepie S, Teplitsky C, Pavard S, et al. (2015) Age-related variation and temporal patterns in the survival of a long-lived scavenger. Oikos. doi: 10.1111/oik.02216

Chapuis J-L, Obolenskaya E V, Pisanu B, Lissovsky AA (2009) Datasheet on Tamias sibiricus. CABI, Wellingford, UK (http://www.cabi.org/isc/).

Choquet R, Lebreton J-D, Gimenez O, et al. (2009) U-CARE: Utilities for performing goodness of fit tests and manipulating CApture-REcapture data. Ecography (Cop) 32:1071-1074. doi: 10.1111/j.1600-0587.2009.05968.x

Clutton-Brock TH (1988) Reproductive success: studies of individual variation in contrasting breeding systems. University of Chicago Press

Clutton-Brock TH, Albon SD, Guinness FE (1985) Parental investment and sex differences in juvenile mortality in birds and mammals. Nature 313:131-133. doi: 10.1038/313131a0

Clutton-Brock TH, Isvaran K (2007) Sex differences in ageing in natural populations of vertebrates. Proc R Soc London B Biol Sci 274:3097-3104. doi: 10.1098/rspb.2007.1138 
Cooch EG, White GC (2014) Program MARK - A Gentle Introduction, 13th ed.

Coulson T, Catchpole EA, Albon SD, et al. (2001) Age, sex, density, winter weather, and population crashes in Soay sheep. Science (80- ) 292:1528-1531. doi: 10.1126/science.292.5521.1528

Descamps S, Boutin S, McAdam AG, et al. (2009) Survival costs of reproduction vary with age in North American red squirrels. Proc R Soc London B Biol Sci 276:1129-1135. doi: 10.1098/rspb.2008.1401

Duriez O, Ens BJ, Choquet R, et al. (2012) Comparing the seasonal survival of resident and migratory oystercatchers: carry-over effects of habitat quality and weather conditions. Oikos 121:862-873. doi: 10.1111/j.1600-0706.2012.20326.x

Efford MG, Borchers DL, Byrom AE (2009) Density estimation by spatially explicit capturerecapture: likelihood-based methods. Model. Demogr. Process. Mark. Popul. Springer U, pp 255-269

Feder C, Martin JGA, Festa-Bianchet M, et al. (2008) Never too late? Consequences of late birthdate for mass and survival of bighorn lambs. Oecologia 156:773-781. doi: $10.1007 / \mathrm{s} 00442-008-1035-9$

Forslund P, Part T (1995) Age and reproduction in birds - Hypotheses and tests. Trends Ecol Evol 10:374-378. doi: 10.1016/S0169-5347(00)89141-7

Garratt M, Lemaitre J-F, Douhard M, et al. (2015) High juvenile mortality is associated with sex-specific adult survival and lifespan in wild roe deer. Curr Biol 25:759-763. doi: 10.1016/j.cub.2014.11.071

Gittleman JL, Thompson SD (1988) Energy allocation in mammalian reproduction. Am Zool 28:863-875.

Grant TA, Shaffer TL, Madden EM, Pietz PJ (2005) Time-specific variation in passerine nest 
survival: New insights into old questions. Auk 122:661-672. doi: 10.1642/00048038(2005)122[0661:TVIPNS]2.0.CO;2

Greenwood PJ (1980) Mating systems, philopatry and dispersal in birds and mammals. Anim Behav 28:1140-1162.

Hamel S, Gaillard J-M, Yoccoz NG, et al. (2010) Fitness costs of reproduction depend on life speed: empirical evidence from mammalian populations. Ecol Lett 13:915-35. doi: 10.1111/j.1461-0248.2010.01478.x

Hardouin LA, Nevoux M, Robert A, et al. (2012) Determinants and costs of natal dispersal in a lekking species. Oikos 121:804-812. doi: 10.1111/j.1600-0706.2012.20313.x

Hardouin LA, Robert A, Nevoux M, et al. (2014) Meteorological conditions influence shortterm survival and dispersal in a reinforced bird population. J Appl Ecol 51:1494-1503. doi: $10.1111 / 1365-2664.12302$

Heldmaier G (1989) Seasonal acclimation of energy requirements in mammals: functional significance of body weight control, hypothermia, torpor and hibernation. In: Wieser W, Erich G (eds) Energy Transform. cells Org. Thieme, Stuttgart, pp 130-139

Hines JE, Kendall WL, Nichols JD (2003) On the use of the robust design with transient capture-recapture models. Auk 120:1151-1158. doi: 10.1642/00048038(2003)120[1151:OTUOTR]2.0.CO;2

Huggins R (1989) On the statistical analysis of capture experiments. Biometrika 76:133-140.

Humphries MM, Thomas DW, Kramer DL (2003) The role of energy availability in mammalian hibernation: a cost-benefit approach. Physiol Biochem Zool 76:165-179.

Kawamichi M (1996) Ecological factors affecting annual variation in commencement of hibernation in wild chipmunks (Tamias sibiricus). J Mammal 77:731-744.

Kendall WL, Bjorkland R (2001) Using open robust design models to estimate temporary 
emigration from capture-recapture data. Biometrics 57:1113-22.

553

554

555

556

557

558

559

560

561

562

563

564

565

566

567

568

569

570

571

572

573

574

575

Kendall WL, Hines JE (1999) Program RDSURVIV: an estimation tool for capture-recapture data collected under Pollock's robust design. Bird Study 46:S32-S38. doi: $10.1080 / 00063659909477229$

Kendall WL, Nichols JD, Hines JE (1997) Estimating temporary emigration using capturerecapture data with Pollock's robust design. Ecology 78:563-578.

Kerbiriou C, Le Viol I, Robert A, et al. (2009) Tourism in protected areas can threaten wild populations: from individual response to population viability of the chough Pyrrhocorax pyrrhocorax. J Appl Ecol 46:657-665. doi: 10.1111/j.1365-2664.2009.01646.x

Kirkwood TBL, Rose MR (1991) Evolution of senescence: late survival sacrificed for reproduction. Philos Trans R Soc Lond B Biol Sci 332:15-24. doi: 10.1098/rstb.1991.0028

Krasnov BR, Morand S, Hawlena H, et al. (2005) Sex-biased parasitism, seasonality and sexual size dimorphism in desert rodents. Oecologia 146:209-217. doi: 10.1007/s00442005-0189-y

Kraus C, Eberle M, Kappeler PM (2008) The costs of risky male behaviour: sex differences in seasonal survival in a small sexually monomorphic primate. Proc R Soc London B Biol Sci 275:1635-1644. doi: 10.1098/rspb.2008.0200

Kraus C, Thomson DL, Künkele J, Trillmich F (2005) Living slow and dying young? Lifehistory strategy and age-specific survival rates in a precocial small mammal. J Anim Ecol 74:171-180. doi: 10.1111/j.1365-2656.2004.00910.x

Laake J, Rexstad E (2014) RMark-an alternative approach to building linear models in MARK. In: Cooch EG, White GC (eds) Progr. MARK A Gentle Introd., 13th ed. pp C$1-\mathrm{C}-113$ 
Lane JE, Boutin S, Speakman JR, Humphries MM (2010) Energetic costs of male reproduction in a scramble competition mating system. J Anim Ecol 79:27-34. doi: 10.1111/j.1365-2656.2009.01592.x

Le Coeur C, Robert A, Pisanu B, Chapuis J-L (2015a) Seasonal variation in infestations by ixodids on Siberian chipmunks: effects of host age, sex, and birth season. Parasitol Res 114:2069-2078. doi: 10.1007/s00436-015-4391-5

Le Coeur C, Thibault M, Pisanu B, et al. (2015b) Temporally fluctuating selection on a personality trait in a wild rodent population. Behav Ecol 26:1285-1291. doi: 10.1093/beheco/arv074

Lebl K, Bieber C, Adamík P, et al. (2011) Survival rates in a small hibernator, the edible dormouse: a comparison across Europe. Ecography (Cop) 34:683-692. doi: 10.1111/j.1600-0587.2010.06691.x

Leyrer J, Lok T, Brugge M, et al. (2013) Mortality within the annual cycle: seasonal survival patterns in Afro-Siberian Red Knots Calidris canutus canutus. J Ornithol 154:933-943. doi: 10.1007/s10336-013-0959-y

Libert C, Dejager L, Pinheiro I (2010) The X chromosome in immune functions: when a chromosome makes the difference. Nat Rev Immunol 10:594-604. doi: 10.1038/nri2815

Lindström J (1999) Early Developnment and fitness in birds and mammals. Trends Ecol Evol $14: 343-348$.

Loison A, Festa-Bianchet M, Gaillard J-M, et al. (1999) Age-specific survival in five populations of ungulates: evidence of senescence. Ecology 80:2539-2554. doi: 10.1890/0012-9658(1999)080[2539:ASSIFP]2.0.CO;2

Marmet J, Pisanu B, Chapuis J-L, et al. (2012) Factors affecting male and female reproductive success in a chipmunk (Tamias sibiricus) with a scramble competition mating system. 
601

602

603

604

605

606

607

608

609

610

611

612

613

614

615

616

617

618

619

620

621

622

623

Marmet J, Pisanu B, Chapuis J-L (2009) Home range, range overlap, and site fidelity of introduced Siberian chipmunks in a suburban French forest. Eur J Wildl Res 55:497504. doi: 10.1007/s 10344-009-0266-3

Marmet J, Pisanu B, Chapuis J-L (2011) Natal dispersal of introduced Siberian chipmunks, Tamias sibiricus, in a suburban forest. J Ethol 29:23-29. doi: 10.1007/s10164-010-02153

Marsot M, Chapuis J-L, Gasqui P, et al. (2013) Introduced Siberian chipmunks (Tamias sibiricus barberi) contribute more to Lyme borreliosis risk than native reservoir rodents. PLoS One 8:e55377. doi: 10.1371/journal.pone.0055377

Moore SL, Wilson K (2002) Parasites as a viability cost of sexual selection in natural populations of mammals. Science (80- ) 297:2015-20188. doi: 10.1126/science.1074196

Neuhaus P, Pelletier N (2001) Mortality in relation to season, age, sex, and reproduction in Columbian ground squirrels (Spermophilus columbianus). Can J Zool 79:465-470. doi: $10.1139 / \mathrm{cjz}-79-3-465$

Noël F, Machon N, Robert A (2013) Integrating demographic and genetic effects of connections on the viability of an endangered plant in a highly fragmented habitat. Biol Conserv 158:167-174. doi: 10.1016/j.biocon.2012.07.029

Obolenskaya E V, Lee M-Y, Dokuchaev NE, et al. (2009) Diversity of Palaearctic chipmunks (Tamias, Sciuridae). Mammalia 73:281-298. doi: 10.1515/MAMM.2009.047

Pisanu B, Obolenskaya E V., Baudry E, et al. (2013) Narrow phylogeographic origin of five introduced populations of the Siberian chipmunk Tamias (Eutamias) sibiricus (Laxmann, 1769) (Rodentia: Sciuridae) established in France. Biol Invasions 15:1201-1207. doi: $10.1007 / \mathrm{s} 10530-012-0375-\mathrm{x}$ 
Pollock KH (1982) A capture-recapture design robust to unequal probability of capture. J Wildl Manage 46:752-757.

Prendergast BJ, Freeman DA, Zucker I, Nelson RJ (2002) Periodic arousal from hibernation is necessary for initiation of immune responses in ground squirrels. Am J Physiol Integr Comp Physiol 282:R1054-R1062. doi: 10.1152/ajpregu.00562.2001

Promislow D (1992) Costs of sexual selection in natural populations of mammals. Proceedings Biol Sci 247:203-210.

R Core Team (2014) R: A Language and Environment for Statistical Computing.

Radchuk V, Johst K, Groeneveld J, et al. (2014) Appropriate resolution in time and model structure for population viability analysis: insights from a butterfly metapopulation. Biol Conserv 169:345-354. doi: 10.1016/j.biocon.2013.12.004

Rexstad E, Burnham KP (1992) User's guide for interactive program CAPTURE. Color. Cooperative Fish and Wildlife Research Unit

Robert A, Paiva VH, Bolton M, et al. (2012) The interaction between reproductive cost and individual quality is mediated by oceanic conditions in a long-lived bird. Ecology 93:1944-1952. doi: 10.1890/11-1840.1

Rödel HG, Bora A, Kaetzke P, et al. (2004) Over-winter survival in subadult European rabbits: Weather effects, density dependence, and the impact of individual characteristics. Oecologia 140:566-576. doi: 10.1007/s00442-004-1616-1

Roff DA (1992) Evolution of life histories: theory and analysis. Springer Science \& Business Media

Schaub M, Vaterlaus-Schlegel C (2001) Annual and seasonal variation of survival rates in the garden dormouse (Eliomys quercinus). J Zool 255:89-96. doi:

10.1017/S0952836901001133 
Skalski JR, Hoffmann A, Smith SG (1993) Testing the significance of individual-and cohortlevel covariates in animal survival studies. Mark. Individ. study bird Popul. Model. Methods, Softw. pp 9-28

Stanley TR, Burnham KP (1999) A closure test for time-specific capture-recapture data. Environ Ecol Stat 6:197-209.

Stearns SC (1989) Trade-offs in life-history evolution. Funct Ecol 3:259-268.

Stearns SC (1992) The evolution of life histories. Oxford: Oxford University Press

Théoret-Gosselin R, Hamel S, Côté SD (2015) The role of maternal behavior and offspring development in the survival of mountain goat kids. Oecologia 178:175-186. doi: $10.1007 / \mathrm{s} 00442-014-3198-\mathrm{x}$

Turbill C, Bieber C, Ruf T (2011) Hibernation is associated with increased survival and the evolution of slow life histories among mammals. Proc R Soc London B Biol Sci 278:3355-3363. doi: 10.1098/rspb.2011.0190

Wang LCH (1989) Ecological, physiological, and biochemical aspects of torpor in mammals and birds. Anim. Adapt. to Cold. Springer Berlin Heidelberg, pp 361-401

West SA, Sheldon BC (2002) Constraints in the evolution of sex ratio adjustment. Science (80- ) 295:1685-1688. doi: 10.1126/science.1069043

White GC, Burnham KP (1999) Program MARK: survival estimation from populations of marked animals. Bird Study 46:S120-S139. doi: 10.1080/00063659909477239

Wilkinson GS, South JM (2002) Life history, ecology and longevity in bats. Aging Cell 1:124-131. doi: doi:10.1046/j.1474-9728.2002.00020.x

Wilson JA, Kelt DA, Van Vuren DH, Johnson ML (2008) Population dynamics of small mammals in relation to production of cones in four types of forests in the northern Sierra Nevada, California. Southwest Nat 53:346-356. doi: 10.1894/MLK-02.1 
Table 1. Description and notation of temporal and group effects used in Huggin's robust design models. Parameters, for which a detailed effect was tested, are listed and correspond to survival (S), capture $(p)$, recapture $(c)$, temporary emigration $\left(\gamma^{\prime \prime}\right)$ and temporary immigration $\left(1-\gamma^{\prime}\right)$ probabilities.

\begin{tabular}{llll}
\hline Type & Notation & Description & Parameters \\
\hline Temporal & $\mathrm{t}$ & Full-time dependance & $S, \gamma^{\prime}, \gamma^{\prime}$, \\
& sess & Session effect & $p, c$ \\
& year & Year effect & $S, p, c, \gamma^{\prime}, \gamma^{\prime}$, \\
& seas & Season effect & $S, p, c, \gamma^{\prime}, \gamma^{\prime}$, \\
& 2 Seas & Only two seasons: active season VS. the fall-winter & $S$ \\
Group & sex & Sex effect & $S, p, c, \gamma^{\prime}, \gamma^{\prime,}$ \\
& b & Birth season effect (spring-born and summer-born individuals) & $S, p, c, \gamma^{\prime}, \gamma^{\prime}$, \\
& a & Age effect - juveniles and adults (> year of birth) & $S, \gamma^{\prime}, \gamma^{\prime}$, \\
& juvbs & Effect of birth season on juveniles only & $S$ \\
Temporary & Markovian & Markovian temporary emigration & $S, p, c, \gamma^{\prime}, \gamma^{\prime}$, \\
migration & Random & Random temporary emigration & $\gamma^{\prime}, \gamma^{\prime}$, \\
\hline
\end{tabular}


676 Table 2. Summary of model selection results for survival (S) in Siberian chipmunks

677 introduced to Forest of Sénart, during the 10-year study (2004-2013). According to the model

678 selection on p, c, $\gamma^{\prime}$ and $\gamma^{\prime \prime}$ (see detailed model selection in Online Resource 2), each model

679 presented in the result table was defined by [ $\gamma^{\prime}$ and $\left.\gamma^{\prime \prime}{ }_{(\text {seas markovian) }} \mathrm{c}_{(\text {sess) }} \mathrm{p}_{(.)}\right]$. Model selection

680 is based on second-order Akaike's Information Criterion (AICc). Number of parameters (np),

681 AICc values and AICc differences between the best model and the current candidate model

$682\left(\Delta_{\mathrm{i}}\right)$ and the Akaike weight $\left(w_{i}\right)$ were reported. Best models occur in bold $\left(\Delta_{\mathrm{i}}<2\right)$. The fully

683 parameterized model, the 11 best models and the models that are referred to in the text were

684 detailed in this table (see complete model selection in Online Resource 2).

\begin{tabular}{|c|c|c|c|c|c|c|}
\hline $\mathrm{N}^{\circ}$ & Models & $\mathrm{np}$ & $\mathrm{AICc}$ & $\Delta_{\mathrm{i}}$ & $w_{i}$ & Deviance \\
\hline$\overline{59}$ & seas $*($ year + sex $)+b * a$ & 73 & 8022.49 & $\mathbf{0}$ & 0.50 & 6449.57 \\
\hline 60 & seas $*($ year + sex $)+$ juvbs & 72 & 8022.54 & 0.05 & 0.48 & 6451.78 \\
\hline 61 & seas $*($ year $+\operatorname{sex})+a$ & 71 & 8028.41 & 5.92 & 0.03 & 6459.80 \\
\hline 62 & seas $*($ year $+a *(b+\operatorname{sex}))$ & 82 & 8034.00 & 11.51 & 0.00 & 6441.56 \\
\hline 63 & $t+\operatorname{sex}+$ juvbs & 69 & 8042.43 & 19.94 & 0.00 & 6478.13 \\
\hline 64 & $t+\operatorname{sex}+b * a$ & 70 & 8042.90 & 20.41 & 0.00 & 6476.44 \\
\hline 65 & 2 Seas $*($ year $+\operatorname{sex})+b * a$ & 61 & 8043.20 & 20.71 & 0.00 & 6496.02 \\
\hline 66 & $t+a *(\operatorname{sex}+b)$ & 71 & 8044.82 & 22.33 & 0.00 & 6476.21 \\
\hline 67 & $t+b * a$ & 69 & 8047.53 & 25.04 & 0.00 & 6483.22 \\
\hline 68 & $t+\operatorname{sex} * b * a$ & 73 & 8048.72 & 26.23 & 0.00 & 6475.80 \\
\hline 69 & $\mathrm{t} * \operatorname{sex}+\mathrm{b} * \mathrm{a}$ & 98 & 8048.77 & 26.28 & 0.00 & 6421.15 \\
\hline 71 & $\mathrm{t}$ & 66 & 8063.55 & 41.06 & 0.00 & 6505.68 \\
\hline 74 & 2 Seas $+($ year + sex $)+b * a$ & 52 & 8085.57 & 63.08 & 0.00 & 6557.48 \\
\hline 76 & year $+\operatorname{sex}+b * a$ & 51 & 8089.38 & 66.89 & 0.00 & 6563.40 \\
\hline 79 & year & 47 & 8101.08 & 78.59 & 0.00 & 6583.53 \\
\hline 80 & seas*sex $+b * a$ & 46 & 8104.18 & 81.69 & 0.00 & 6588.72 \\
\hline 81 & seas $* \operatorname{sex}+a$ & 44 & 8104.69 & 82.20 & 0.00 & 6593.43 \\
\hline 84 & $\operatorname{sex}+a$ & 40 & 8115.52 & 93.03 & 0.00 & 6612.62 \\
\hline
\end{tabular}


$90 \quad a$

93

$94 \quad$ seas

95

$\mathrm{t} * \operatorname{sex} * \mathrm{~b} * \mathrm{a}$
39

38

40

269

* interaction terms; + additive terms $\begin{array}{llll}8120.15 & 97.66 & 0.00 & 6619.33\end{array}$

$\begin{array}{llll}8122.04 & 99.55 & 0.00 & 6623.30\end{array}$

$\begin{array}{llll}8124.89 & 102.40 & 0.00 & 6621.98\end{array}$

$\begin{array}{llll}8386.01 & 363.52 & 0.00 & 6340.96\end{array}$ 
687

688

689

690

691

692

693

694

695

696

697

698

699

700

701

702

703

704

705

706

707

708

Figure 1 Yearly survival probability \pm SE (a) in relation with monthly survival rates estimated at each season $\pm \mathrm{SE}$ (b) in the population of Siberian chipmunks introduced to the suburban Forest of Sénart and monitored from 2004 to 2013. The mean annual survival was indicated in grey (dashed line, panel a). The yearly and monthly survival rates were estimated from Models 79 and 71, respectively. Some monthly survival probabilities were poorly estimated (blank) and the annual survival rate in 2013 is not well-estimated (i.e., large SE).

Figure 2 Monthly survival probabilities \pm SE of Siberian chipmunks for (a) each season (spring, summer, fall-winter), (b) according to age, sex and birth season. Spr.-born and sum.born refer to spring-born and summer-born individuals, respectively. The survival rates were estimated from Models 94 and 80 for (a) and (b), respectively.

Figure 3 Correlation between estimated fall-winter survival probabilities and (a) the oak fructification index and (b) the mean fall-winter temperatures. Open circles represent the estimates from a time dependent model (standard errors SE are indicated by vertical bars). The continuous line is the regression line from the survival model constrained by the temporal covariate (SE is indicated by the grey shade; Models 103 and 108, respectively, Online Resource 4).

Figure 4 Correlation between seasonal survival probabilities (spring, summer and fall-winter) and the adult density of chipmunks in April, June and July respectively. Open circles represent the monthly estimates from a time dependent model (standard errors SE are indicated by vertical bars). The continuous line is the regression line from the survival model constrained by the adult density ( $\mathrm{SE}$ is indicated by the grey shade; Model 118, Online Resource 4). 
Figure 1

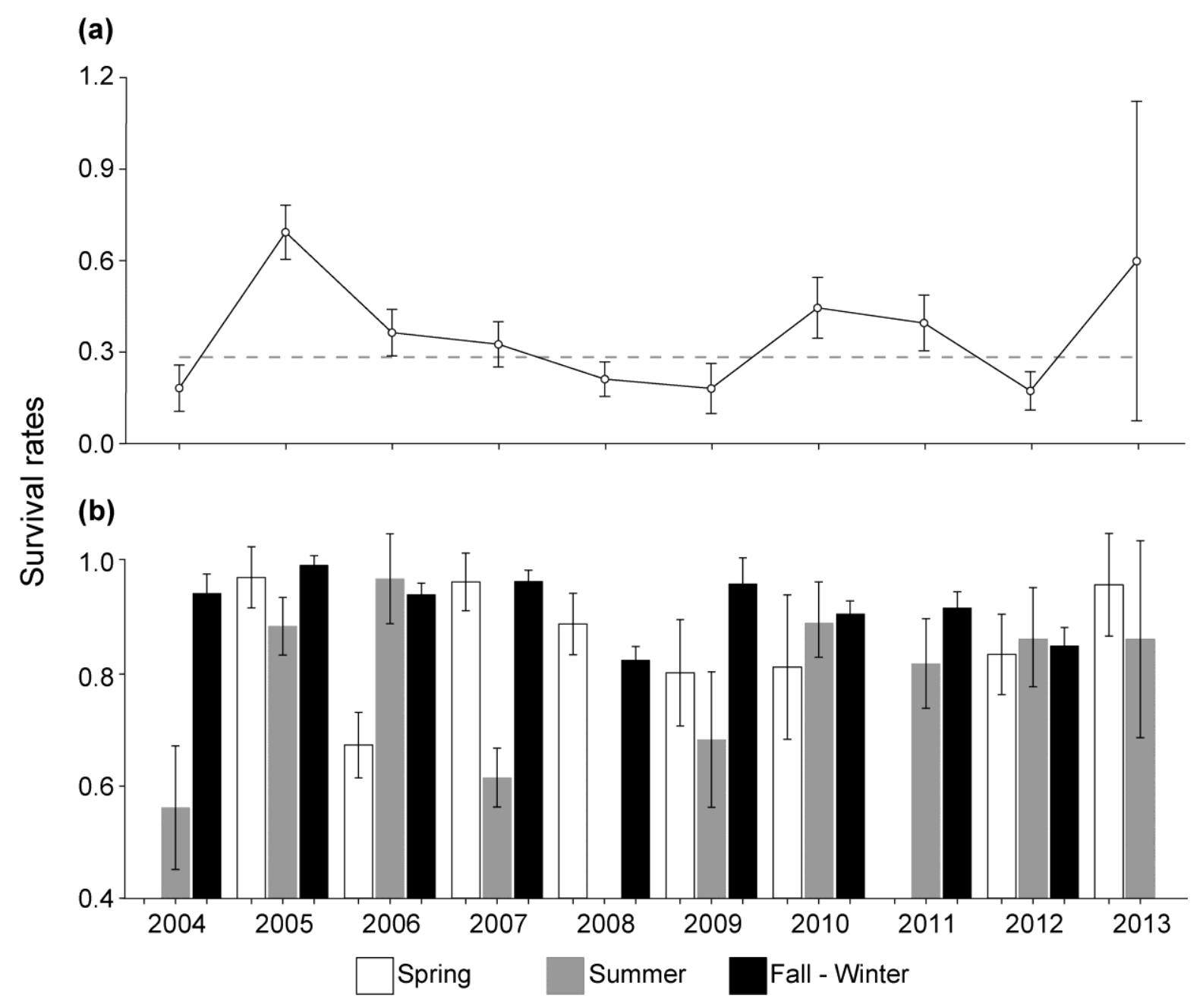


Figure 2

(a)
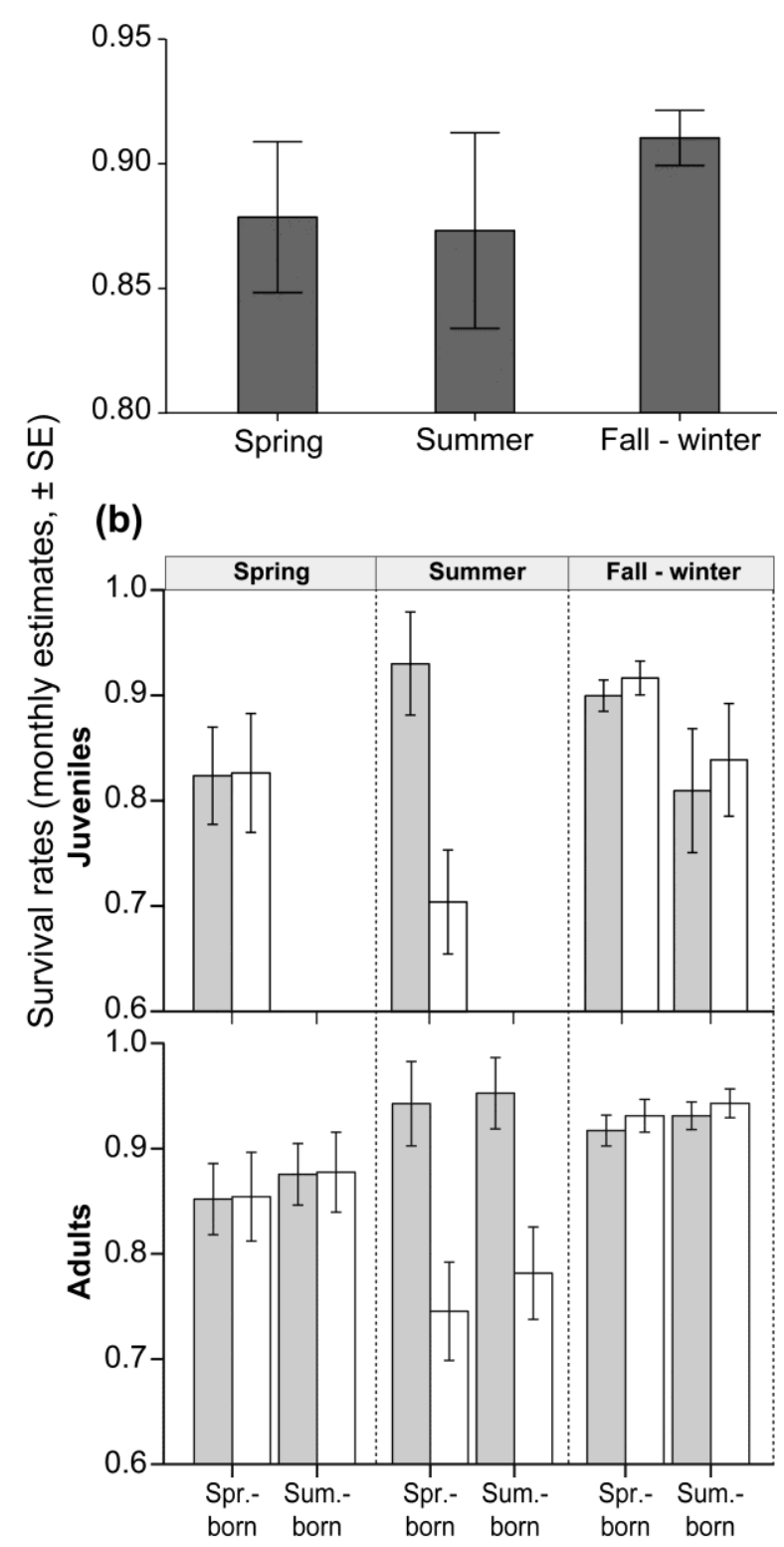
Figure 3

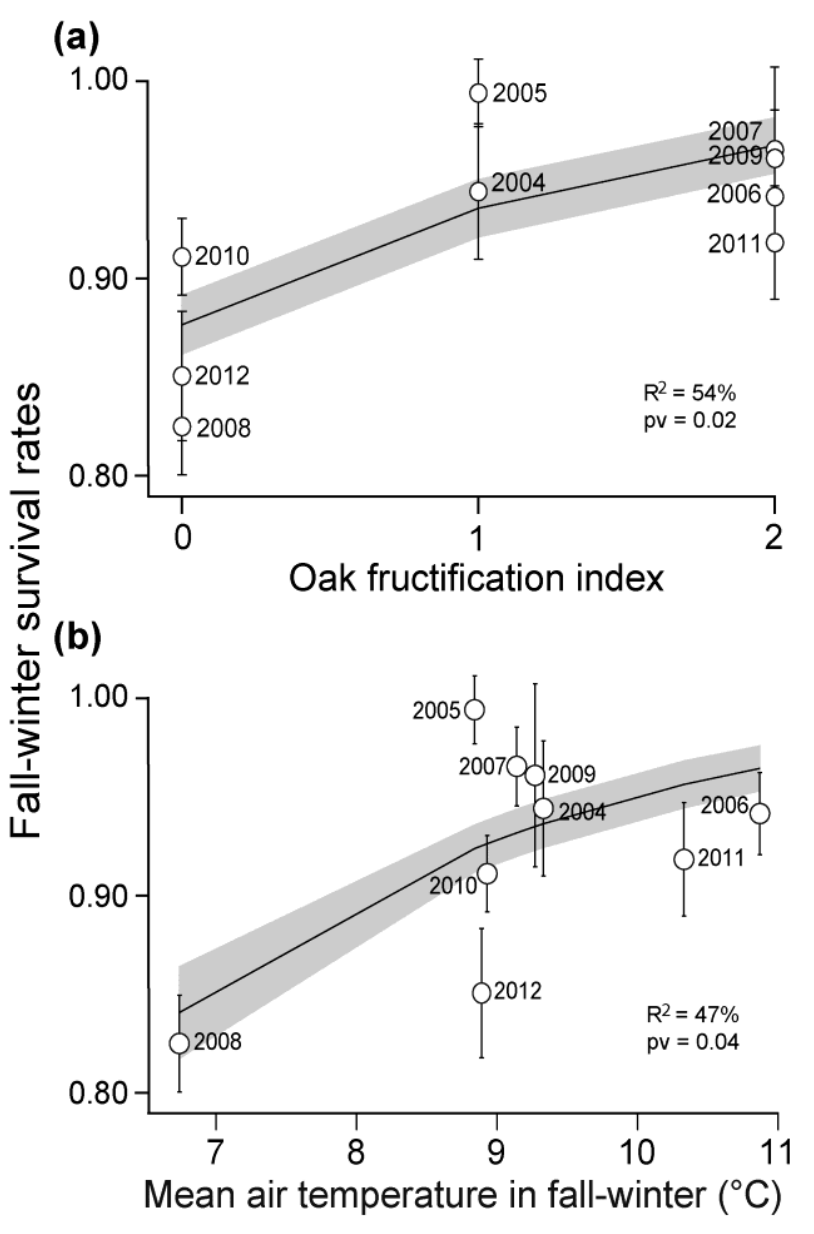


Figure 4

(a)

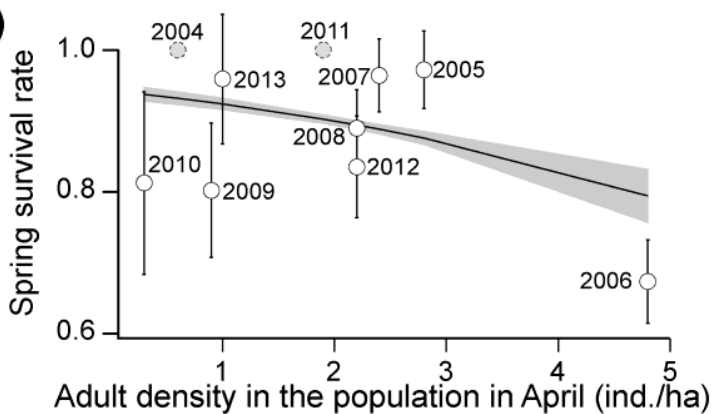

(b)

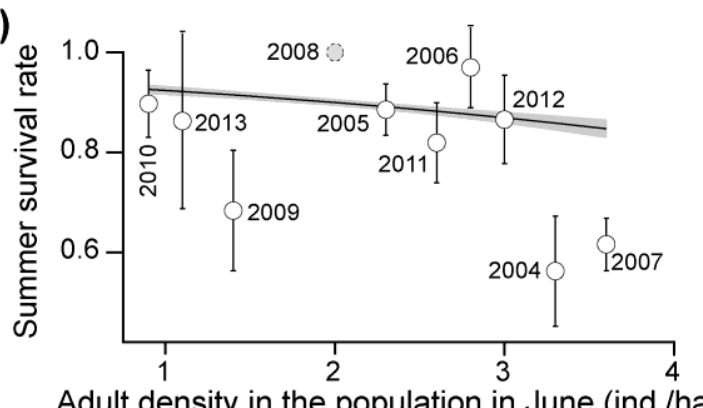

(c)

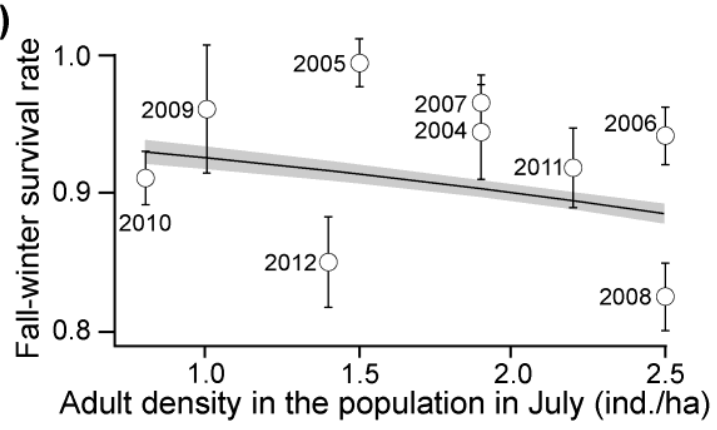

